\title{
Velocity anisotropy and trend in Niger Delta, Nigeria
}

\author{
Emmanuel Aniwetalu' ${ }^{1}$ [ Emmanuel Anakwuba ${ }^{1} \cdot$ Juliet llechukwu ${ }^{1}$
}

Received: 14 May 2020 / Accepted: 4 March 2021 / Published online: 22 March 2021

(c) The Author(s) 2021

\begin{abstract}
In geophysical data interpretation, matching the vertical velocity direction from seismic data with borehole-derived velocities is a challenging task because seismic-derived velocities are faster than borehole recorded velocities. This geophysical phenomenon is caused by velocity anisotropy. In this study, we used an empirical approach to estimate the degree of velocity anisotropy in the study area. The results showed that the delta anisotropy in sandstone beds varies from $-2.5 \%$ to $7.2 \%$ while most of them concentrate between $3.2 \%$ and $6.1 \%$. The epsilon ranges between $-6.4 \%$ and $9.3 \%$ while many of them concentrate between $3.2 \%$ and $7.2 \%$. The gamma varies from $-6.3 \%$ to $7.3 \%$ while most of them concentrate between $1.2 \%$ and $5 \%$. At shale beds, delta anisotropy varies from $-11.2 \%$ to $11.1 \%$ but most of them concentrate between $4.3 \%$ and $10.5 \%$. The epsilon varies from $-7.2 \%$ to $14.5 \%$ while most of them concentrate between $4.5 \%$ and $10.5 \%$. The gamma varies from $6.4 \%$ to $8.2 \%$ while majority of them concentrate between $2 \%$ and $5.3 \%$. The results indicate that the study area is weakly to moderately anisotropic with shale beds having higher anisotropy values than sandstone beds. This probably results from preferential alignment of clay mineral orientations which also affect in situ velocity propagation. Three distinct velocity gradients (low, moderate and very high) were identified in the study area. These velocities vary erratically but showed northeast-southwest increase in velocities. Thus, the need to derive correction factors for individual wells for improved exploration success.
\end{abstract}

Keywords Anisotropy $\cdot$ Velocity $\cdot$ Delta $\cdot$ Epsilon $\cdot$ Gamma

\section{Background to the study}

The term anisotropy can be defined as the dependent of seismic velocity upon an angle or a variation of physical properties that are dependent on the direction of its measurement (Thomsen 1986). Anisotropy can also be considered as an anomaly caused by directional variations which must be removed or corrected. Although, in quantitative reservoir study, it can be exploited to improve interpretation especially in vertical fracture characterization. However, in seismic processing, it is important to consider the effects of anisotropy in processing flow. But in most cases, this important stage in reservoir interpretation is often ignored on the assumption that elastic medium is isotropic while in reality, it is anisotropic (Thomsen 1988 and Jones et al. 2003). Sedimentary rocks are fundamentally anisotropic and the

Emmanuel Aniwetalu

eu.aniwetalu@unizik.edu.ng

1 Department of Applied Geophysics, Nnamdi Azikiwe University, Awka, Nigeria most common velocity anisotropy is transverse isotropy also known as polar anisotropy, where the velocity is constant on the surface of a cone about some axis, known as the axis of symmetry (Jones et al. 2003; Alkhalifah and Tsvankin (1995). In other words, the velocity is azimuthally invariant but only varies as a function of angle from the symmetry axis. This is of different types and includes vertical transverse isotropy (VTI), horizontal traverse isotropy (HTI) and tilted traverse isotropy (TTI). Niger delta geological setting is favored by vertical transverse isotropy (VTI) probably due to the sequential sand-shale layering.

Thomsen (1986) introduced three major constants considered as effective parameters for measuring anisotropy especially for vertical transverse isotropy (VTI). They are known as near vertical anisotropy or delta ( $\delta)$, P-wave anisotropy or epsilon $(\varepsilon)$ and S-wave anisotropy or gamma $(\gamma)$. Among these, near vertical anisotropy does not involve the horizontal velocity at all in its definition and thus the most critical measure of anisotropy. The P-wave anisotropy controls the normal move out of the compressional wave arrivals especially in a horizontally layered sequence. It is an influential

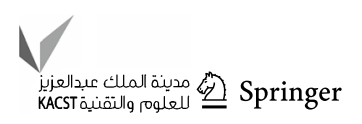


parameter for seismic wave travelling close to the vertical transverse isotropy (VTI) which has a hexagonal symmetry and fine layering where individual particles are preferentially aligned. But near vertical and S-wave anisotropy represents the percentage difference between the vertical and horizontal P-wave velocities and polarized shear wave respectfully. Tsvankin et al. (1994) proposed a technique of inverting anisotropic non-hyperbolic normal move out equation for the estimation of these anisotropic parameters. They concluded that the determination of delta anisotropy $(\delta)$ which has short offset move out is relatively easy while P-wave anisotropy $(\mathcal{E})$ which carries long offset move out information needs a measure of horizontal velocity which is difficult to measure. Toldi (1999) highlighted the importance of near vertical anisotropy in processes like depth imaging and stated that it must be measured with the aid of well control to give integrity in the interpretation. But generally, estimation of anisotropic parameters in VTI is dependent on the horizontal layered media where seismic waves tend to propagate at different velocities in different direction. The variations in the velocities are dependent on the various sequences of lithologies and seismic velocities tend to travel more quickly along the bedding planes than perpendicular to the layered boundaries (Thomsen 1986; Jakobsen and Johansen 2000; Hudson 1981; Johansen et al. 2004; Rudd et al. 2003, and Kaushik 2009).

This geophysical phenomenon is the reason why seismicderived velocities are faster and often higher than borehole (well) recorded velocities and the resultant effect is that the structural depths interpreted from surface seismic would be shallower than their true depths in the subsurface. This mispositioning of the depth may lead to unimaginable errors during data interpretation if the knowledge of the velocity anisotropy in the area is ignored. Therefore, the focus of the study is to use an empirical method to quantify velocity anisotropy, velocity trend and also recommend appropriate measures that could improve exploration success in the study area.

\section{Geologic framework of the study area}

The study area is located in Isako Field in the south-western parts of Niger Delta (Fig. 1). The Niger Delta basin ranks among the world's most prolific province of hydrocarbon and also known as the world's largest Tertiary Delta System. It is situated on the West African Continental Margin at the apex of the Gulf of Guinea. For the past 50 years, hydrocarbon exploitations in the basin have been on the increase because of its major geological features that account for the entire hydrocarbon production at present-day Nigeria (Whiteman 1982). The Niger Delta basin is framed on the northwest by subsurface continuation of the West African
Shield known as the Benin Flank while the eastern edge of the basin coincides with Calabar Flank and to the south of the Oban Massif.

However, during continental break-up, the basin formed the site of a triple junction which was fed by river Benue, Niger and Cross rivers. This drained more than $10^{5} \mathrm{~km}^{2}$ of continental lowland Savannah with different depositional environments and geomorphic units. Reijers (1997) classified lithostratigraphic units of the Niger Delta Basin into three major subdivisions; an Upper Delta Top Facies; a Middle Delta Front Lithofacies; and a Lower Pro-Delta Lithofacies. According to Short and Stauble (1967), these correspond, respectively, with the loose continental sands of the Benin Formation (Oligocene-Recent), Paralic Agbada Formation (Eocene-Recent) and the under compacted shales of the Akata Formation (Paleocene-Recent) respectfully. The Delta-Top Benin Formation which overlies the Delta-Front Agbada Formation consists of continental sands and gravel while the composition of its subsurface reflects the presentday Quaternary land and swamp outcrops. Agbada Formation is major petroleum bearing unit which represents the seat of petroleum explorations and exploitations in Niger Delta. This is because most prolific reservoirs are embedded in the intercalated sand-shale sequence of the Formation. The Formation consists of shoreface, channel sands and alternation of sands and shales which represent the current beach ridges (Reijers 2011). The Akata formation composed mainly of turbidities and continental slope channel fills such as marine shales, with sandy and silty beds. However, various types of depositional environment and morphological units such as coastal flats, ancient/modern sea, river and lagoonal beaches, sand bars/flats, flood plains, seasonally flooded depressions, swamps, backswamps, abandoned and modern river/creek channels have been recognized in the basin but the study area cut across active and abandoned coastal beaches, saltwater mangrove swamps and Freshwater swamps, backswamps, deltaic plain, alluvium and meander belt. These areas remained the seat of onshore hydrocarbon exploration in Niger Delta.

\section{Materials and methods}

The data used in this study include suite of well logs with set of dipole sonic log (compressional and shear wave logs), density and gamma ray logs and 2006 processed vintage of the ISAKO PSDM seismic data. The seismic data were acquired in 2006 using short offset (3000 m cable length) and processing was carried out on the data to address shallow channels and velocity variation, amidst attenuating steeply dipping long period multiples that were somewhat retained in the data. 


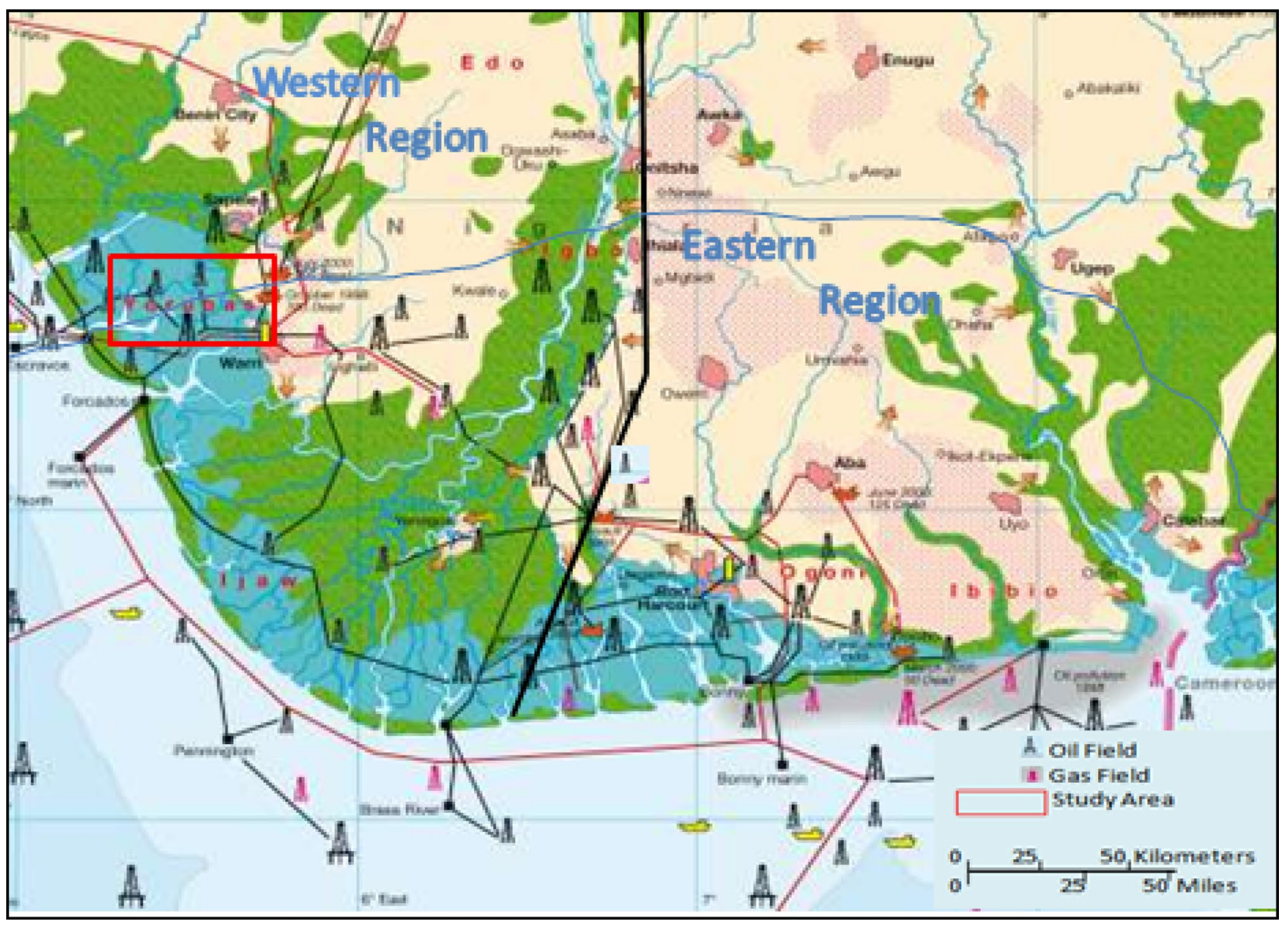

Fig. 1 Map of Niger Delta showing the location of the study area

\section{Velocity anisotropy modeling}

In vertical traverse isotropic (VTI) media, anisotropy can be modeled by defining the following parameters namely $\varepsilon$ (p-wave anisotropy), $\delta$ (near vertical anisotropy) and $\gamma$ (shear wave anisotropy).

Let consider an expression given by Hudson (2000) for the effective stiffness tensor in cracked media for long wave-length seismic waves

$C i j k l=C^{0} i j k l+C^{1} i j k l+C^{2} i j k l$

where $C^{1} i j k l, C^{2} i j k l$ and $C^{0} i j k l$ denote the first-order, the second-order perturbation of the isotropic elastic constants, and uncracked medium, respectively. Using crack density and the lame constant, the first-order and second-order perturbations can be computed. Interestingly, one can also find an expression for an anisotropic medium for a set of cracks through the effective stiffness tensor which are often expressed in two indices notations given as.
Stiffness tensor for an isotropic medium

$$
C_{a \beta}^{0}=\left(\begin{array}{llllll}
\lambda+2 \mu & \lambda & \lambda & & & \\
& \lambda+2 \mu & \lambda & & & \\
& & \lambda+2 \mu & & \\
& & & & \mu & \\
& & & & \mu & \\
& & & & & \mu
\end{array}\right)
$$

where $\lambda$ and $\mu$ are Lambda Rho and Mu Rho respectfully. And,

Stiffness tensor for a transverse isotropic medium with vertical axis of symmetry. 


$$
C_{a \beta}^{0}=\left(\begin{array}{lllll}
\mathrm{C}_{11}\left(\mathrm{C}_{11}-2 \mathrm{C}_{66}\right) & \mathrm{C}_{13} & & & \\
\mathrm{C}_{11} & \mathrm{C}_{13} & & & \\
& \mathrm{C}_{13} & & & \\
& & \mathrm{C}_{44} & & \\
& & & \mathrm{C}_{44} & \\
& & & & \mathrm{C}_{66}
\end{array}\right)
$$

These elastic stiffness tensors define an elastic medium and also control the pattern of wave travel through it. For instance, in earth model (Fig. 2), wave travels more quickly along the layers than across the layer boundaries. The vertically travelling waves across the boundaries are said to be out of plane. This could be out of plane compressional modulus $\left(\mathrm{C}_{33}\right)$ or out of plane shear modulus $\left(\mathrm{C}_{44}\right)$. The horizontally travelling waves are said to be in plane which could also be in-plane compressional modulus $\left(\mathrm{C}_{11}\right)$ or in-plane shear modulus $\left(\mathrm{C}_{66}\right)$. $\mathrm{C}_{13}$ is an important constant that controls the shape of these wave surfaces (Sayers 1994; Berryman et al. 1999).

These parameters $\left(\mathrm{C}_{11}, \mathrm{C}_{13}, \mathrm{C}_{33}, \mathrm{C}_{44}, \mathrm{C}_{66}\right)$ are referred to as five independent components of elastic stiffness tensors and they can be expressed as follows:

$$
\begin{aligned}
& C_{11}=4 M-4 S+\frac{(1-2 T)^{2}}{R} \\
& C_{13}=\frac{1-2 T}{R} \\
& C_{33}=\lambda+2 \mu \\
& C_{44}=\mu \\
& C_{66}=M
\end{aligned}
$$

Where,

$M=\Phi \mu_{1}+(1-\Phi) \mu_{2}$

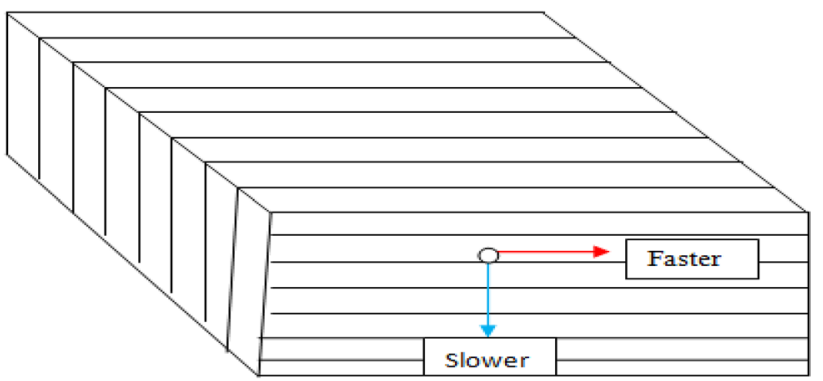

Fig.2 Modes of wave propagation in elastic earth model
$R=\frac{\Phi}{\left(\lambda_{1}+2 \mu_{1}\right)}+\frac{(1-\Phi)}{\left(\lambda_{2}+2 \mu_{2}\right)}$

$S=\Phi \theta_{1} \mu_{1}+(1-\Phi) \theta_{1} \mu_{2}$

$T=\Phi \theta_{1}+(1-\Phi) \theta_{2}$

$\theta=\frac{V s}{V p}$

$\lambda$ and $\mu$ are the first and second Lame parameters, respectively, $\Phi$ is the porosity while $\Theta$ is the phase angle.

Following Ogagarue (2007), we define the parameters $\mathrm{M}, \mathrm{R}, \mathrm{S}$ and $\mathrm{T}$ in terms of the Lame parameters $\lambda$ and $\mu$, the volume fraction $\Phi$ the ratio of compressional and shear wave velocities in a medium for a stack of two layers. The parameter $\mathrm{M}$ is for a stack of two layers that are controlled by the porosity of the upper and shear moduli of each layer; $\mathrm{R}$ is governed by the porosity of the upper layer, bulk and shear moduli of the layers; $\mathrm{S}$ is a dimensionless parameter which is influenced by porosity, Vs to $\mathrm{Vp}$ ratio and the shear moduli of the layers while $\mathrm{T}$ is defined in terms of porosity and velocity ratio only.

For the above sets of the equations to become suitable for this study, they were modified into these forms.

$C_{33} i=p^{i} V p^{2 i}$

$C_{44}^{i}=p^{i} V s^{2 i}$

$C_{13} i=\frac{1-2 T}{R}$

$C_{66}^{i}=\Phi^{i} C_{44} i+\left(1-\Phi^{i}\right) C_{44} i+1$

$$
\Phi^{i}=\left(\frac{V s^{i}}{V p^{i}}\right)^{2}, \Phi^{i+1}=\left(\frac{V s^{i+1}}{V p^{i}+1}\right)^{2}
$$

$C_{11}^{i}=C_{66}^{i}-4 \Phi^{i} \theta^{i} C_{44}^{i}+\left(1-\Phi^{i}\right) \theta^{i+1} C_{44}^{i+1} \frac{(1-2 T)^{2}}{R}$

Where $T=\Phi \theta_{1}+(1-\Phi) \theta_{2}$

$R={\frac{\Phi}{C_{33} i}}^{i}+{\frac{1-\Phi^{i}}{C_{33} i}}^{i}$

$\mathrm{p}, \mathrm{Vp}, \mathrm{Vs} \Phi, \mathrm{i}, \mathrm{i}+$ lare the density, compressional velocity, shear wave velocity, porosity, present depth and next depth interval, respectively.

Using Eqs. 9, 10, 11, 12, 13, the five elastic stiffness tensors for a transverse isotropic medium with vertical axis of symmetry can be deduced. 
However, to quantify the degree of velocity anisotropy present in the sediments, the following relations were used.

$\varepsilon=\frac{C_{11}-C_{33}}{2 C_{33}}$

$\delta=\frac{\left(C_{13}-C_{44}\right)^{2}-\left(C_{13}-C_{44}\right)^{2}}{2 C_{33}\left(C_{13}-C_{44}\right)}$

$\gamma=\frac{C_{66}-C_{44}}{2 C_{44}}$

Where parameter $\varepsilon$ is epsilon ( $\mathrm{P}$-wave anisotropy), $\delta$ is delta (near vertical anisotropy) and $\gamma$ is gamma ( $\mathrm{S}$-wave anisotropy). According to Tsvankin, (1997), the near vertical anisotropy $\delta$ defines the second derivative of the P-wave phase velocity function at vertical incidence and he showed that for weak anisotropy, $\delta$ can be approximated as follows:

$\delta=\frac{\left(C_{13}-2 C_{44}-C_{33}\right)}{C_{33}}$

\section{Data transformation and estimation}

The interval transit times were transformed to vertical $\mathrm{P}$-wave and $\mathrm{S}$-wave velocities in feet/second ( $\mathrm{ft} / \mathrm{s}$ ) using Eq. 18 and 19, respectively. Density logs were transformed to porosity $(\Phi)$ values using Eq. 20.

$\Delta \mathrm{tp}=\frac{V p}{0.305}$

$\Delta t s=\frac{V s}{0.305}$

$\rho_{b}=\frac{\Phi\left\{p_{m a}-\rho_{f}\right\}}{p_{m a}}$

Where $\Delta t p$ and $\Delta t s$ are the interval transit time recorded by compressional log and shear sonic $\log$, respectively. $\rho_{\text {ma }}$ is the density of rock matrix, taken to be $2.65 \mathrm{~g} / \mathrm{cc}(2,650 \mathrm{~kg} /$ $\left.\mathrm{m}^{3}\right), \rho_{\mathrm{b}}$ is the formation bulk density recorded by density tool, and $\rho_{\mathrm{f}}$ is density of fluid, taken to be $1.08 \mathrm{~g} / \mathrm{cc}(1,080$ $\mathrm{kg} / \mathrm{m}^{3}$ ). The average rock density in the sandstones from exploration wells is about $2.66 \mathrm{~g} / \mathrm{cm}^{3}$ while that of shale

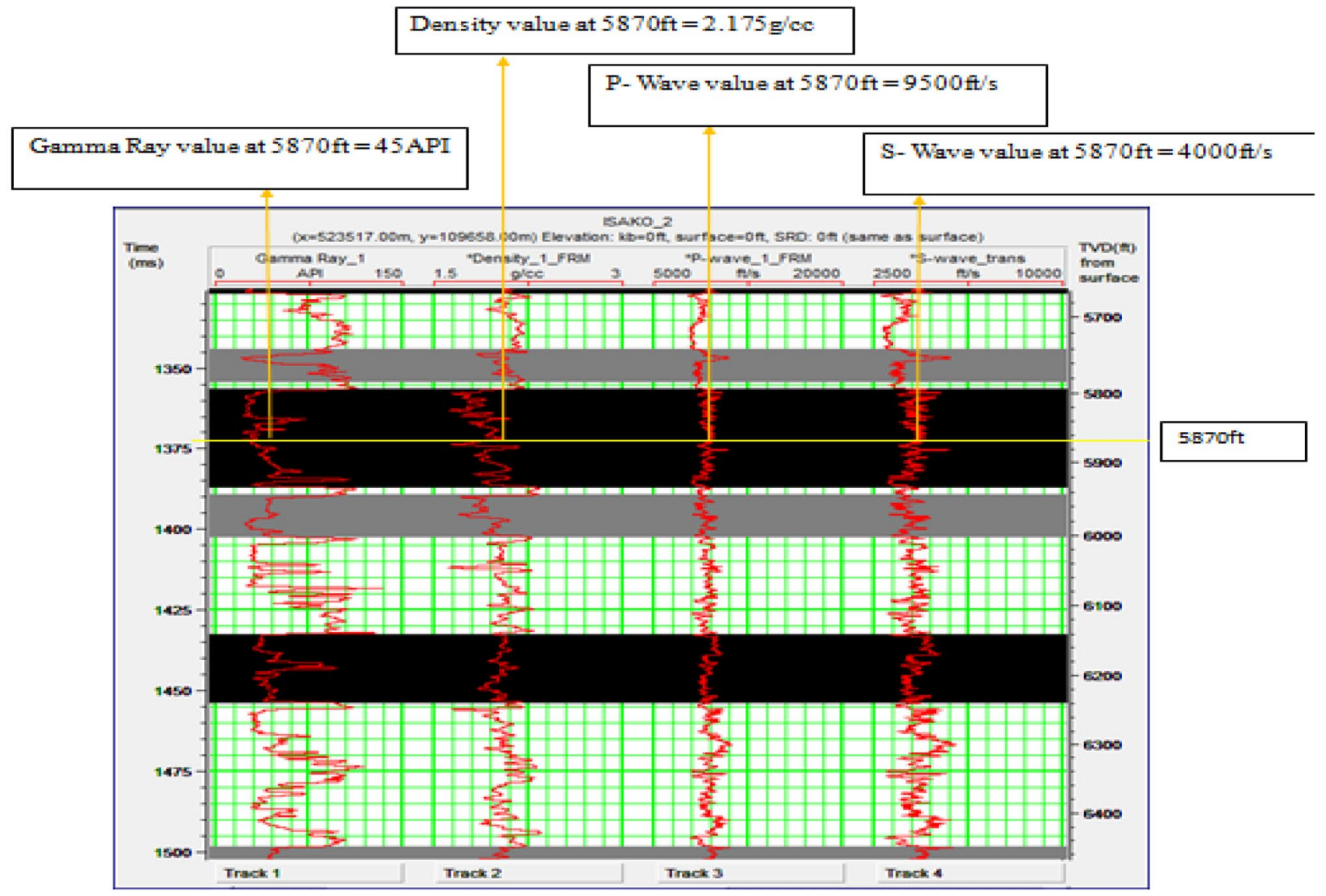

Fig.3 Direct estimation of well log values at 5870ft depth interval 
is assumed to be $2.65 \mathrm{~g} / \mathrm{cm}^{3}$. The fluid density determined using electrical resistivity log depends on whether the well encountered water or hydrocarbons.

As shown in Fig.3, gamma ray, density, compressional and shear wave velocity values can be directly estimated from well $\log$ s at any chosen interval. For instance, at depth interval of 5870ft and 5873ft (next sample interval), the gamma ray (API), density $(\mathrm{g} / \mathrm{cc}), \mathrm{P}$-wave $(\mathrm{ft} / \mathrm{s})$ and $\mathrm{S}$-wave $(\mathrm{ft} / \mathrm{s})$ readings were directly estimated from the well logs (Fig.3). Similar parameters were also estimated at $6050 \mathrm{ft}$ depth interval (Fig.4). The extracted P-wave and $\mathrm{S}$-wave values in feet/per second were transformed to meter/per second using Eq. 18 and 19, respectively. The

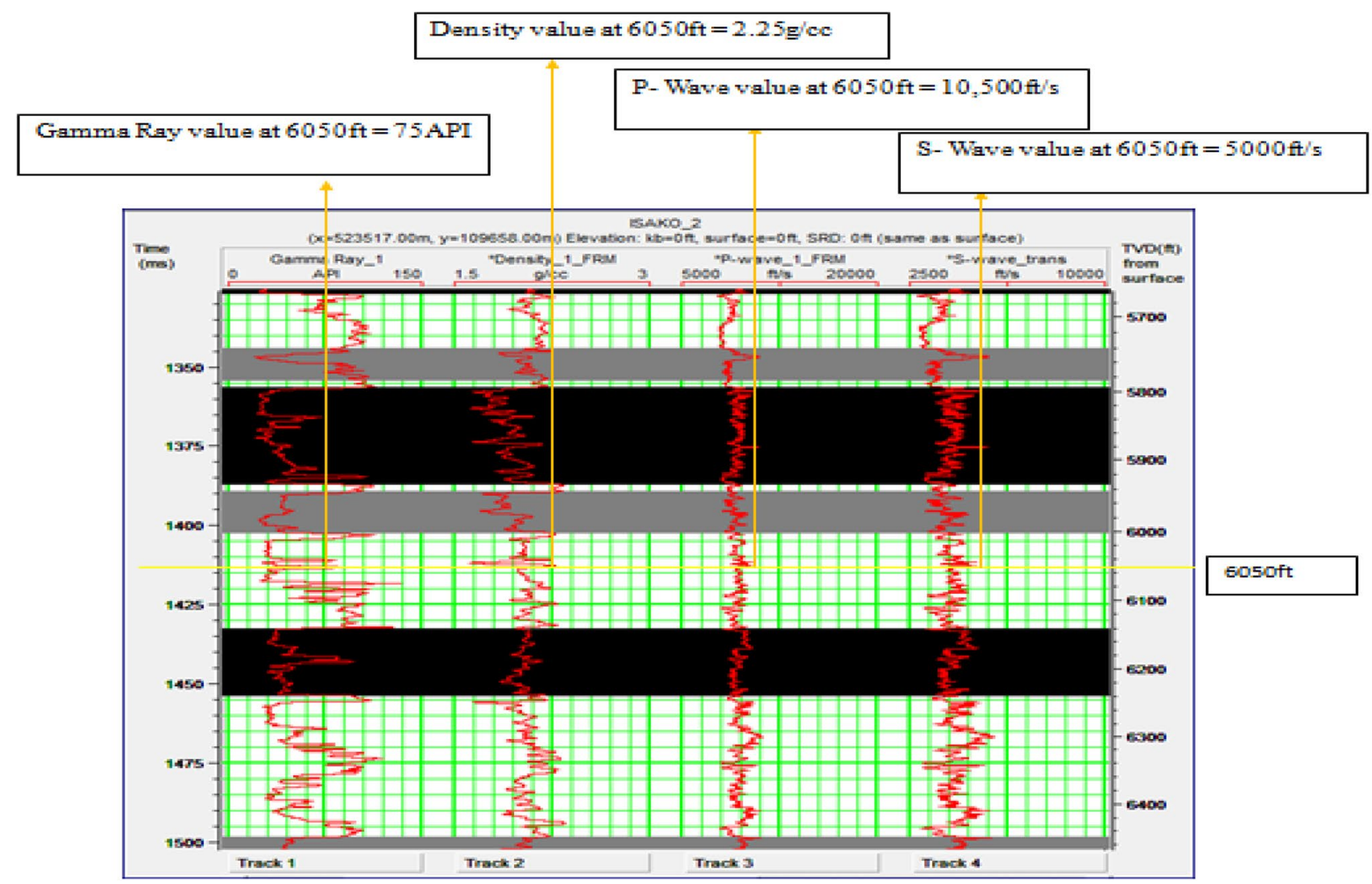

Fig.4 Direct estimation of well log values at $6050 \mathrm{ft}$ depth interval

Table 1 The log readings and the transformed values at the depth level of $5870 \mathrm{ft}$, $5873 \mathrm{ft}$ and $1560 \mathrm{ft}$

Table 2 The computed density, gamma ray, velocities, elastic stiffness tensors and anisotropic parameters at $5870 \mathrm{ft}$ sand $5873 \mathrm{ft}$

\begin{tabular}{llll}
\hline Well log parameters & $\begin{array}{l}\text { Well log Values 1570ft } \\
\text { (Sandstone bed) }\end{array}$ & $\begin{array}{l}\text { Well Log Values 1573ft } \\
\text { (Sandstone bed) }\end{array}$ & $\begin{array}{l}\text { Well log Values } \\
\text { 1560ft (Shale bed) }\end{array}$ \\
\hline Gamma ray & $45 \mathrm{API}$ & $37.5 \mathrm{API}$ & 75 API \\
DT(Compressional log) & $9500 \mathrm{ft} / \mathrm{s}(2 \mathrm{~S} 98 \mathrm{~m} / \mathrm{s})$ & $8,750 \mathrm{ft} / \mathrm{s}(2,669 \mathrm{~m} / \mathrm{s})$ & $10,500 \mathrm{fts}(3203 \mathrm{~m} / \mathrm{s})$ \\
DT (Shear wave log) & $4000 \mathrm{ft} / \mathrm{s}(1220 \mathrm{~m} / \mathrm{s})$ & $3625 \mathrm{ft} / \mathrm{s}(1,106 \mathrm{~m} / \mathrm{s})$ & $5000 \mathrm{ft} / \mathrm{s}(1525 \mathrm{~m} / \mathrm{s})$ \\
Rhob (Density) & $2.2 \mathrm{~g} / \mathrm{cc}(28.66 \%)$ & $2.25 \mathrm{~g} / \mathrm{cc}(25.47 \%)$ & $2.25 \mathrm{~g} / \mathrm{cc}(25.47 \%)$ \\
\hline
\end{tabular}

\begin{tabular}{|c|c|c|c|c|c|c|c|c|c|c|c|c|c|}
\hline $\begin{array}{l}\text { Depth } \\
\text { Ft }\end{array}$ & $\begin{array}{l}\text { Den } \\
\mathrm{g} / \mathrm{cc}\end{array}$ & $\begin{array}{l}\text { GR } \\
\text { API }\end{array}$ & Poro & $\begin{array}{l}\mathrm{Vp} \\
\mathrm{m} / \mathrm{s}\end{array}$ & $\begin{array}{l}\mathrm{Va} \\
\mathrm{m} / \mathrm{s}\end{array}$ & $\begin{array}{l}\mathrm{Cu} \\
\mathrm{MPa}\end{array}$ & $\begin{array}{l}\mathrm{Cl} 3 \\
\mathrm{MPa}\end{array}$ & $\begin{array}{l}\mathrm{C} 33 \\
\mathrm{MPa}\end{array}$ & $\begin{array}{l}\mathrm{C} 44 \\
\mathrm{MPa}\end{array}$ & $\begin{array}{l}\text { Qs } \\
\mathrm{MPa}\end{array}$ & delta & epsilon & Gamma \\
\hline 70 & 2.20 & 45 & 0 . & 28 & 20 & 22 & 13.4 & 47 & 3.27 & 3.04 & 0.115 & -0 & -0.012 \\
\hline 73 & 2.25 & 37 & 0.254 & 2668 & 1,105 & 23.14 & 1 & 15.67 & 2.75 & 3 & 0.016 & 0.238 & 0.46 \\
\hline 6050 & 2.25 & 75 & 0.254 & 3203 & 1525 & 23.21 & 13.20 & 17.22 & 3.10 & 6.22 & 0.15 & 0.22 & 0.24 \\
\hline
\end{tabular}


density values were transformed into standard porosity values using Eq. 20.

The log readings at depth interval of $5870 \mathrm{ft}, 5873 \mathrm{ft}$, and $6050 \mathrm{ft}$ and their corresponding conversions are shown in table 1 while their equivalent elastic stiffness tensors and anisotropic parameters are shown in table 2.

However, with density, gamma ray, compressional and shear wave velocities from well logs already known, five independent elastic stiffness tensors can be calculated using Eqs. (9, 10, 11, 12, 13) while epsilon, delta and gamma anisotropy can also computed at different depth intervals using Eqs. 14,15 and 16 respectfully.

\section{Method of velocity depth modeling and trend analysis}

In subsurface velocity modeling, we used seismic volume and well log data to set up a typical 3D velocity model in depth domain using Pro4D tool of Hampson-Russell Software (HRS). The aim was to produce 3D seismic velocity depth model of the subsurface measured in feet per seconds (ft/s) where velocity depth maps at various depth intervals can be extracted with interpolation guided by well logs. The well logs data were imported through well log Explorer tool of HRS and the amplitude unit and name of the corresponding log types were defined. The well log depth domain range starts from 449 to $9996 \mathrm{ft}$ with sample interval of $0.5 \mathrm{ft}$ while seismic volume displayed range from $0-6000 \mathrm{~ms}$ (two-way time) with sample interval of $8 \mathrm{~ms}$. However, to create subsurface velocity depth profile that could show the subtle lateral velocity variation, we build $3 \mathrm{D}$ velocity model using seismic volume and the control wells or amplitude source. The available wells to be included in the model were selected. The grid geometry needed for accessing the model traces within the display and the processing window was defined. We chose the amplitude unit (ft/s) for P-wave or $\mathrm{S}$-wave and name of the logs for building the corresponding log type. The domain type (depth) and range of the output model were specified. The horizons in depth domain were created from the top and model geometry was defined. However, using model trace filtering option, we apply a blocked trace by taking the average within the horizon layer and fully processed 3D velocity depth model which showed subsurface velocity variations was created (Fig. 5).

Therefore, we created velocity depth profile at various depth intervals by producing the slices of velocity depth

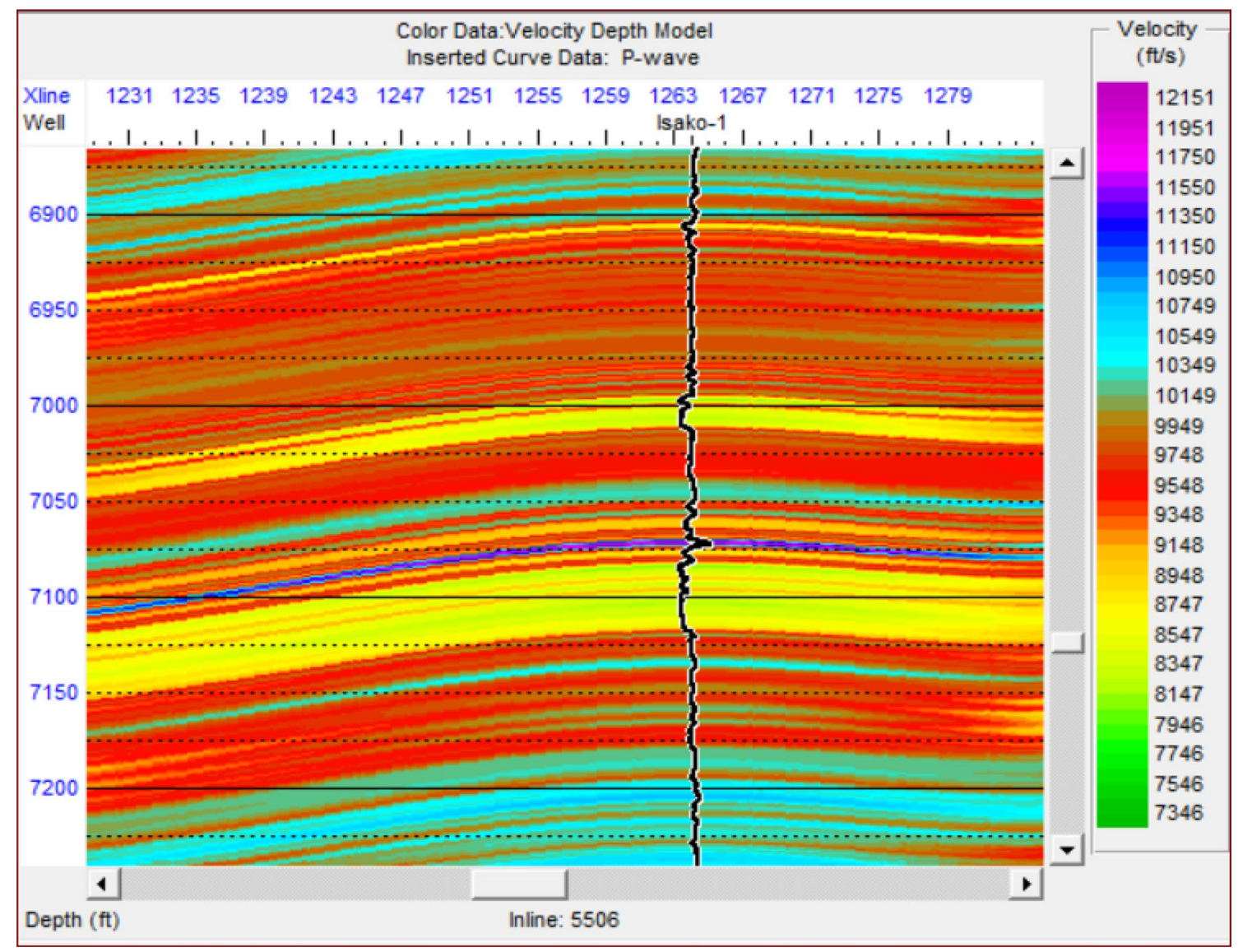

Fig. 5 P-wave velocity depth Model 
Table 3 Velocity anisotropy at selected depths of sandstone layers

\begin{tabular}{lllllcccc}
\hline Sample wells & Depth (Ft) (MD) & $\begin{array}{l}\text { Near vertical } \\
\text { anisotropy } \\
(\delta) \%\end{array}$ & $\begin{array}{l}\text { P-wave } \\
\text { anisotropy } \\
(\varepsilon) \%\end{array}$ & $\begin{array}{l}\text { Shear wave } \\
\text { anisotropy } \\
(\gamma) \%\end{array}$ & Depth(Ft) (MD) & $\begin{array}{l}\text { Near Vertical } \\
\text { anisotropy()\% }\end{array}$ & $\begin{array}{l}\text { P-wave } \\
\text { Anisot- } \\
\text { ropy()\% }\end{array}$ & $\begin{array}{l}\text { Shear wave } \\
\text { anisotropy()\% }\end{array}$ \\
\hline Isako-1 & 5855 & -1.20 & 2.40 & -4.20 & 5870 & 4.11 & 7.30 & 2.42 \\
Isako-2 & 5839 & -2.5 & 3.3 & 3.2 & 5860 & -2.0 & -1.3 & 1.2 \\
Isako-3 & 5980 & 4.3 & 5.1 & -4.0 & 6031 & 4.0 & 5.0 & 3.0 \\
Isako-4 & 5843 & 3.2 & 4.3 & 5.2 & 5891 & 3.2 & 5.3 & -4.2 \\
Isako-5 & 6000 & 6.3 & 7.2 & 4.0 & 6046 & 4.2 & 2.3 & 2.0 \\
Isako-6 & 5849 & 0.00 & 0.0 & 2.0 & 5870 & 5.1 & -1.6 & 1.2 \\
Isako-7 & 5848 & 4.2 & -1.2 & 3.0 & 5869 & 6.1 & 7.3 & 7.3 \\
Isako-8 & 6001 & -3.2 & 6.2 & 2.6 & 6040 & 5.3 & -6.4 & 4.1 \\
Isako-9 & 5858 & 6.3 & 8.4 & 5.0 & 5906 & 5.1 & -4.1 \\
Isako-10 & 6300 & -2.1 & 3.6 & 2.4 & 5921 & 0.0 & -6.3 \\
Isako-11 & 5855 & 6.1 & -5.2 & 5.3 & 5879 & 5.12 & 0.0 \\
Isako-12 & 5854 & 7.2 & 9.3 & 5.3 & 5881 & 4.7 & 0.0 \\
\hline
\end{tabular}

Table 4 Velocity anisotropy at selected depths of shale layers

\begin{tabular}{|c|c|c|c|c|c|c|c|c|}
\hline Sample wells & $\begin{array}{l}\text { Depth }(\mathrm{Ft}) \\
(\mathrm{MD})\end{array}$ & $\begin{array}{l}\text { Near vertical } \\
\text { anisotropy } \\
(\delta) \%\end{array}$ & $\begin{array}{l}\text { P-wave } \\
\text { anisotropy } \\
(\varepsilon) \%\end{array}$ & $\begin{array}{l}\text { Shear wave } \\
\text { anisotropy } \\
(\gamma) \%\end{array}$ & $\begin{array}{l}\text { Depth }(\mathrm{Ft}) \\
(\mathrm{MD})\end{array}$ & $\begin{array}{l}\text { Near Vertical } \\
\text { anisotropy }(\delta) \%\end{array}$ & $\begin{array}{l}\text { P-wave } \\
\text { Anisotropy }(\varepsilon) \%\end{array}$ & $\begin{array}{l}\text { Shear wave } \\
\text { anisotropy }(\gamma) \%\end{array}$ \\
\hline Isako-1 & 5966 & 8.3 & 7.2 & 6.4 & 5970 & 9.20 & 7.00 & 5.00 \\
\hline Isako-2 & 6051 & -7.3 & 6.4 & 7.2 & 6081 & 6.5 & 10.4 & 5.4 \\
\hline Isako-3 & 5766 & 5.5 & 10.2 & 4.1 & 5805 & 4.3 & -4.2 & -6.5 \\
\hline Isako-4 & 5700 & -11.2 & 9.34 & 4.3 & 5712 & 3.3 & 4.3 & -2.2 \\
\hline Isako-5 & 5972 & 7.20 & 13.7 & 5.5 & 5841 & 4.5 & 6.1 & 5.3 \\
\hline Isako-6 & 6063 & 11.1 & 12.2 & 7.3 & 5990 & 10.5 & 12.7 & 6.42 \\
\hline Isako-7 & 5778 & 8.2 & 6.2 & 5.5 & 6090 & 7.2 & 14.2 & 4.2 \\
\hline Isako-8 & 5706 & -4.3 & -7.2 & 3.7 & 5820 & 6.4 & 4.2 & 4.1 \\
\hline Isako-9 & 5978 & 8.0 & 5.5 & -6.4 & 5718 & 7.3 & 6.4 & 4.2 \\
\hline Isako-10 & 6072 & -5.2 & 6.6 & -4.2 & 5841 & 3.5 & 3.1 & 2.3 \\
\hline Isako-11 & 5790 & 8.0 & 5.6 & 8.2 & 5993 & 5.2 & -3.7 & 6.5 \\
\hline Isako-12 & 5712 & 5.6 & 7.0 & -6.3 & 6099 & 5.6 & 8.9 & 5.5 \\
\hline
\end{tabular}

maps from the 3D velocity depth model. The velocity depth maps revealed velocity variation at different depth intervals. But to obtain the subsurface velocity trend, we produced the Isopach maps that reflect the thickness of the deposited beds created at different horizons by subtracting the lower surface (base) from the upper layer (top) because velocity increase or decrease is strongly dependent on thickness variation of the sediments. This has offered a solution for an improved exploration and development problems associated with the velocity depth imaging and positioning of a wide range of subsurface geological structures.
Table 5 Average velocity anisotropy in sand and shale layers in western Niger Delta

\begin{tabular}{lll}
\hline Anisotropy parameters & Sandstone layers & Shale Layers \\
\hline Near vertical anisotropy & $-2.5 \%$ to $7.2 \%$ & $-11.2 \%$ to $11.1 \%$ \\
P-wave anisotropy & $-6.4 \%$ to $9.3 \%$ & $-7.2 \%$ to $14.5 \%$ \\
S-wave anisotropy & $-6.3 \%$ to $7.3 \%$ & $6.4 \%$ to $8.2 \%$ \\
\hline
\end{tabular}




\section{Results and discussions}

At sandstone beds, average near vertical anisotropy (delta) varies from $-2.5 \%$ to $7.2 \%$. The P-wave anisotropy (epsilon) values range between $-6.4 \%$ and $9.3 \%$ while the localized S-wave anisotropy (gamma) varies from $-6.3 \%$ to $7.3 \%$ (Table 5). However, most of the near vertical and P-wave anisotropy concentrate within the range of $3.2 \%$ to $6.1 \%$ and $3.2 \%$ to $7.2 \%$ respectfully while S-wave anisotropy $(\gamma)$ concentrates between $1.2 \%$ and $5 \%$. The results of computed anisotropic parameters from sandstone beds at different depths are expressed in percentage as shown in Table 3. However, at the shale beds, average near vertical anisotropy varies from $-11.2 \%$ to $11.1 \%$. The P-wave anisotropy varies from $-7.2 \%$ to $14.5 \%$ while the Localized S-wave anisotropy varies from $6.4 \%$ to $8.2 \%$. But generally, the percentage of near vertical and P-wave anisotropy have its major peaks between $4.3 \%$ to $10.5 \%$ and $4.5 \%$ to $10.5 \%$ respectfully while the S-wave anisotropy range between $2 \%$ to $5.3 \%$. The computed anisotropic parameters from shale beds at different depths are expressed in percentage in Table 4 while the average velocity anisotropy in both sand and shale beds are shown in Table 5 .

Careful study of the above results revealed varying velocity anisotropy values in the two major rock types in the study area. Shale beds showed higher velocity anisotropy values than sandstone beds but generally the velocity anisotropy in the study area is moderately to weakly anisotropic. This suggests that the study area is intrinsically anisotropic with shale beds having relatively high velocity anisotropy values than sandstone beds. However, shale accounts for about $60-70 \%$ in every stratigraphic column and often referred to as clay rich sedimentary rocks. Clay minerals are the abundant kind of all shale constituting about 50-60 wt. \% of most shale. Therefore, relative increase in velocity anisotropy in shale may be related to preferred clay mineral orientation, textural contents and crustal growth processes. High values of shale anisotropy may also be favored by geologic processes such as disperse state of clay deposition, slow mechanical compaction or digenetic recrystallization. These geologic processes enhance alignment in clay domains thus causing an increase in shale anisotropy in large scale. But in sandstones beds, the mineral grains are mostly non-flaky, silty and biotubated. These could reduce grain alignments thus making sandstones beds less anisotropic. Sandstone anisotropy may also be affected by the environment of deposition. For instance, in oxic bottom water which is conducive to more biological activities, larger fraction of silt-sized materials may disrupt fabric alignments thus making the bed less anisotropic. Therefore, to obtain quality reservoir characterization workflow in this weakly anisotropic setting, anisotropy correction factor need to be derived so as to establish a good trend for individual wells. This can help to create accurate 3D velocity anisotropic field using interpreted seismic horizons as control for improved exploration success. But this also depends on the knowledge of velocity trend which was also quantified through $3 \mathrm{D}$ velocity depth model where velocity depth maps at different subsurface intervals were created as evident in (Fig. 6a-d).

Figure $6 \mathrm{a}, \mathrm{b}$ presents the $\mathrm{P}$-wave and S-wave velocity maps at depths of $5870 \mathrm{ft}$ while Fig. $5 \mathrm{c}$, d shows P-wave and S-wave velocity maps at depths of 6072ft. As evident in the velocity depth maps, toward the seashore (SW) the P-wave and shear wave velocities increase and vary erratically from $9100 \mathrm{f} / \mathrm{s}$ to about $9300 \mathrm{ft} / \mathrm{s}$ and $4047 \mathrm{ft} / \mathrm{s}$ to about $4100 \mathrm{ft} / \mathrm{s}$, respectively. They decrease continuously toward the inland in northeast direction. Both P-wave and S-wave velocities shared similar pattern of velocity trend but S-wave velocity is about $45 \%$ to 55\% lower than P-wave velocities. However, three distinct velocity gradients were identified and characterized as very low (green-yellow color codes), moderate (red -blue color codes) and very high (pink color code) velocity gradients (Fig. 6a-d). Despite few velocity inversions, the velocity showed northeast-southwest increase in velocity. Velocity increases in area where there is high sediment thickness as evident in the Isopach maps which showed flat contour maps of the study area that reflect the thickness of the deposited beds (Fig. 7 and Fig. 8). However, toward the seashore there is high thickening of the sediments as indicated in blue and pink color codes. This high thickening of the sediment also corresponds with very high velocity gradients while zones of low velocity gradients reflect sediment thinning. This, however, suggests that the rate of velocity propagation in the subsurface depends on sediment thickness. Although, several factors such as compaction, synsedimentary structures like growth faults and clay diapers may also have.

Affected velocity and anisotropy in different scales in the study area. Sediment compaction is often accompanied with increase in velocity, decrease in sediment anisotropy and porosity with depth. The depth range where such mechanical compaction is more pronounced, very weak near vertical anisotropy is often recorded. But in areas where there are slow sediment compaction, synsedimentary structures and clay diapers, velocity inversion usually occurs. This explains why velocity sometimes do not follow normal trend of increase in velocity with depth as evident in some velocity maps of the study area. But generally, velocity increases with depth because as sediments are deposited, the underlying sediment become more compacted which often lead to the expulsion of pore fluids from the pore spaces. The continuous deposition and compaction of the sediments result to normal compaction trend with a decrease in porosity and anisotropy.

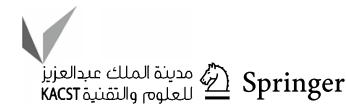




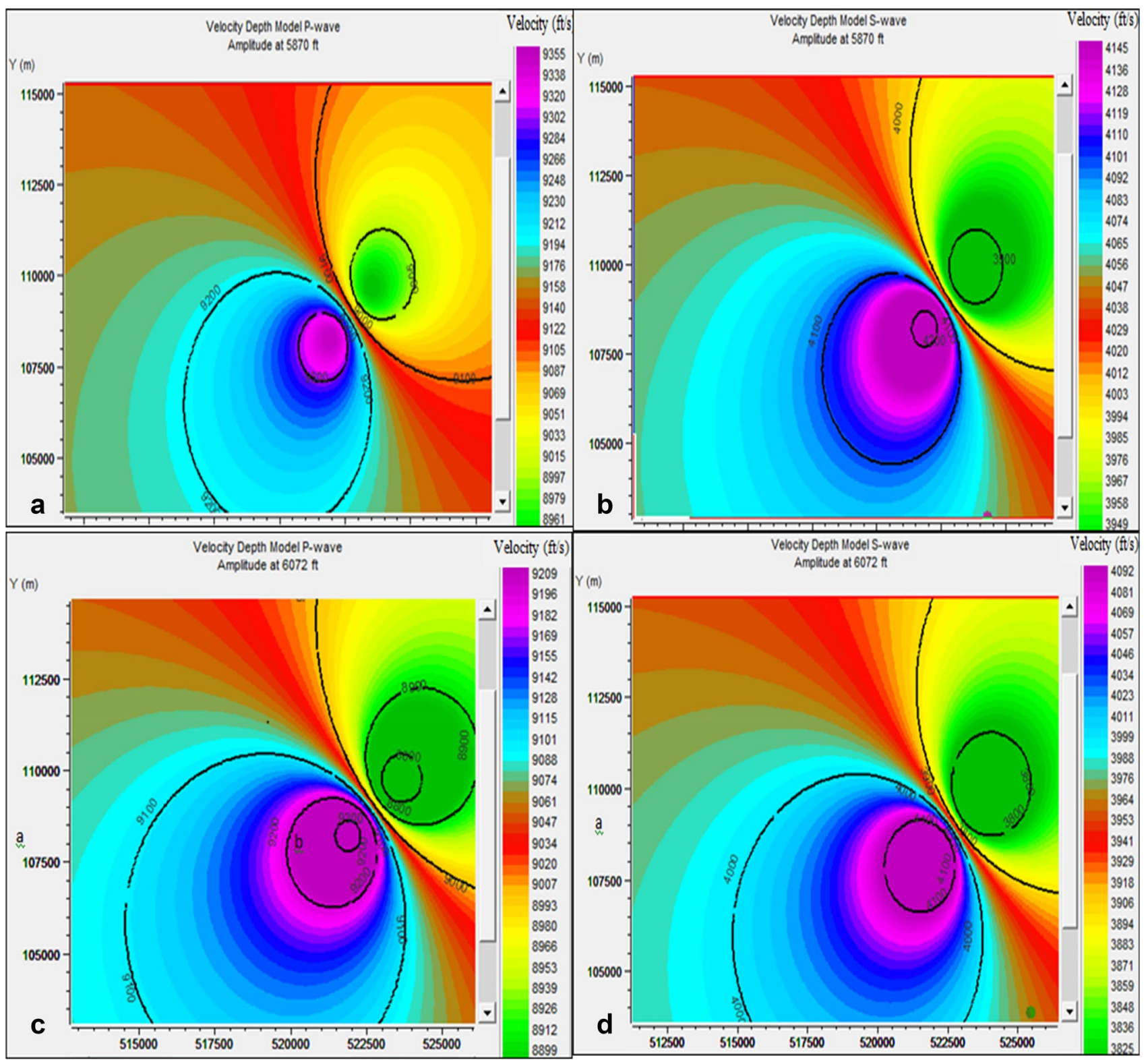

Fig.6 a Velocity depth maps of P-wave at 5870ft b Velocity depth maps of S-wave at 5870ft $\mathbf{c}$ Velocity depth maps of P-wave at $6072 \mathrm{ft} \mathbf{d}$ S-velocity at depth interval $6072 \mathrm{ft}$

\section{Conclusions}

In this study, an empirical approach was used to derive the elastic stiffness tensors and estimate the degree of velocity anisotropy present in the sediment. The range of the anisotropic values shows that the study area is weakly to moderately anisotropic with percentage of anisotropy values higher in shale beds than sandstone beds. The higher anisotropy observed in shale may be attributed to platelike structure of clay minerals which are often elongated and preferential aligned in shale domain while in sandstone beds, biotubations, non-flaky and silt minerals are common and these reduce grain alignment thus making them less anisotropic. However, the results showed that sediment anisotropy in the study area is significant and thus, could pose a very serious exploration risks arising from depth mispositioning between well logs and seismic data if it is ignored. Thus, it becomes important to derived anisotropy correction factor so as to establish a good trend for individual wells before seismic to well ties. This is 


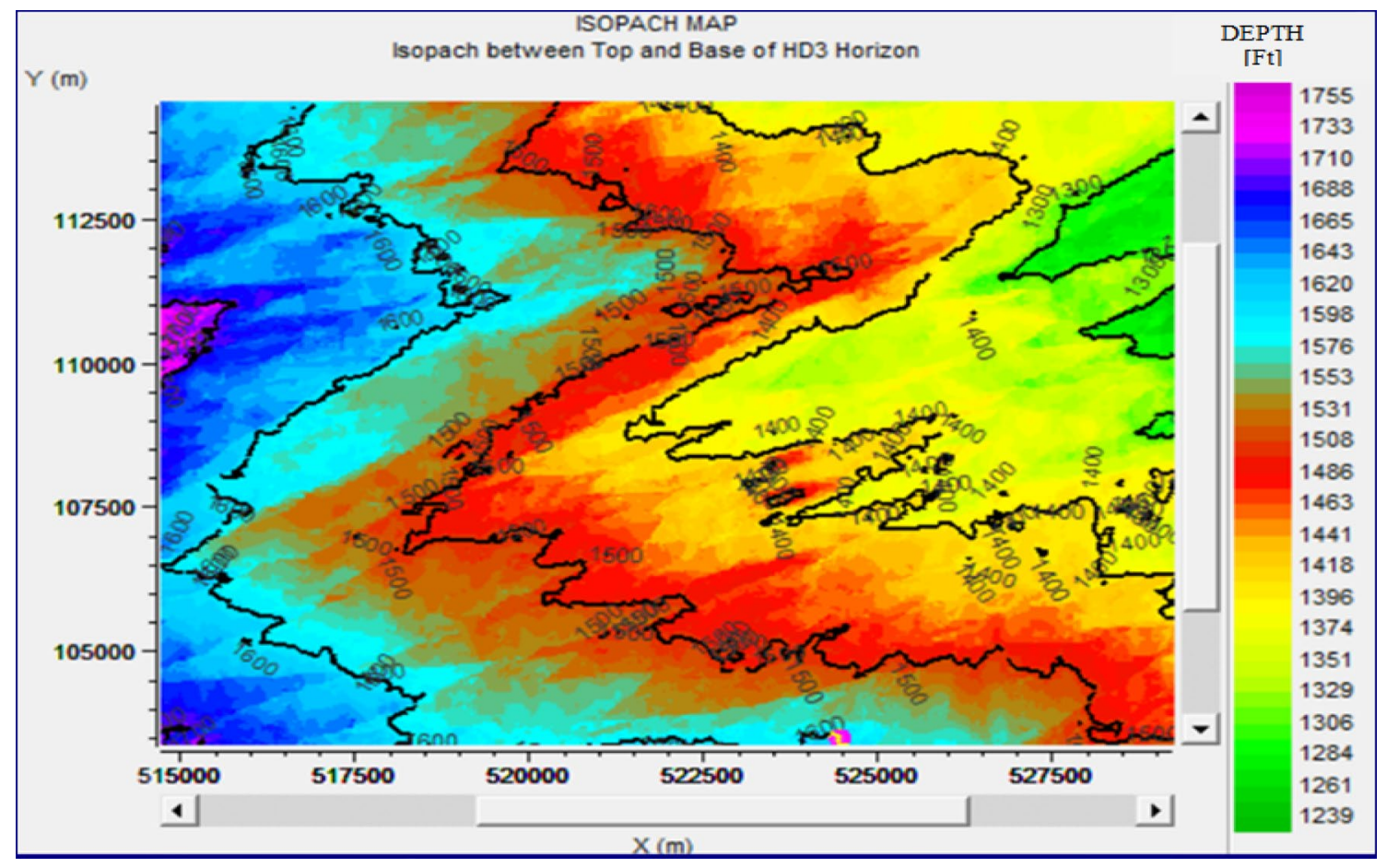

Fig.7 The Isopach map of HD3 Horizon in depth domain

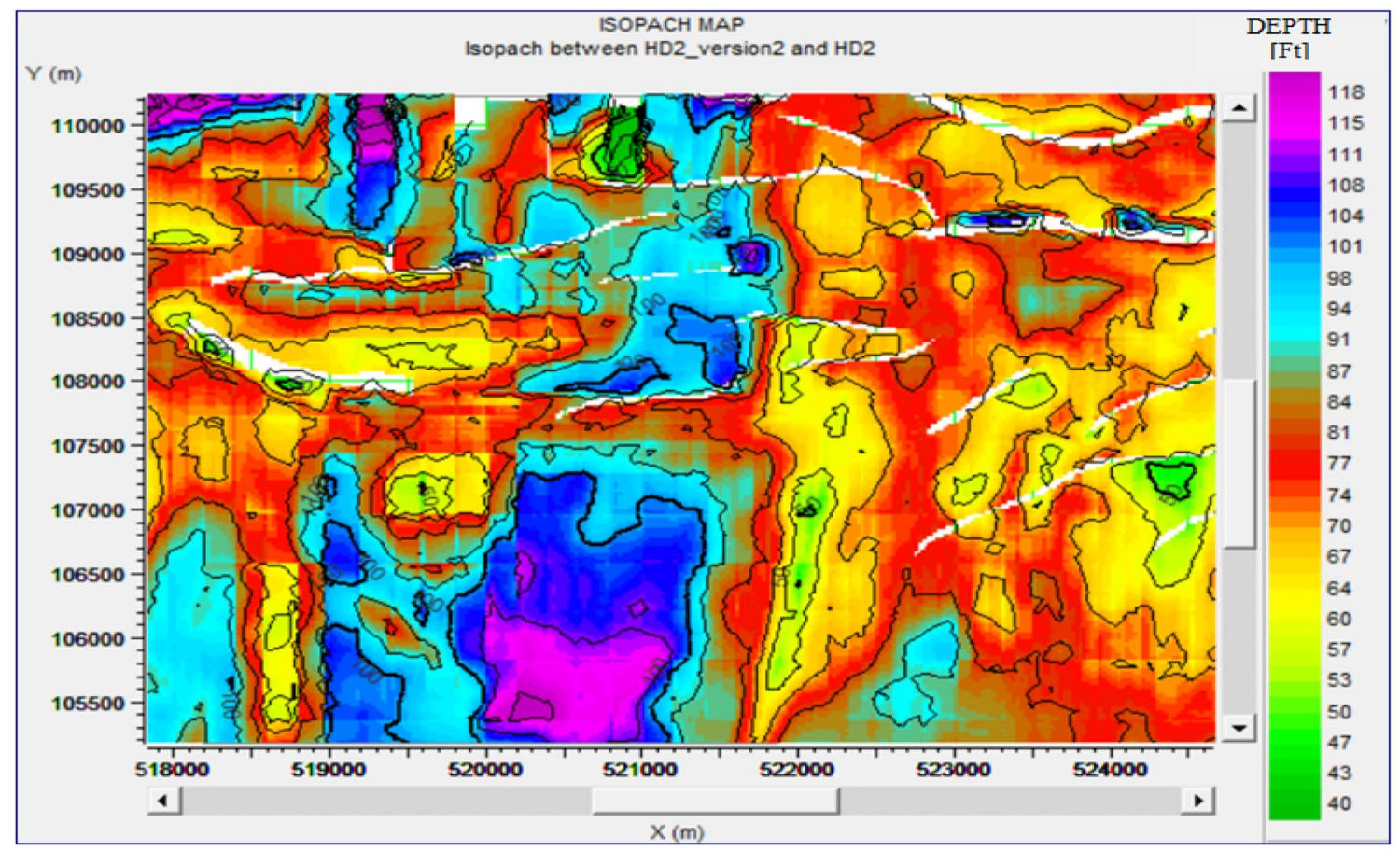

Fig. 8 The Isopach map between HD2 version2 and HD2 
hoped to improve reservoir interpretation and thus maximize hydrocarbon productions.

Acknowledgements We want to thank the Shell Petroleum Development Commission in Port Harcourt, Nigeria for providing data used for this research. Our special thanks go to the staff of the workstation unit of the Department of Applied Geophysics, Nnamdi Azikiwe University, Awka for the unrelenting assistance provided during the data analysis.

Funding I hereby declare that there is no funding for this article.

\section{Declarations}

Conflict of interest The authors declared that they have conflict of interest.

Open Access This article is licensed under a Creative Commons Attribution 4.0 International License, which permits use, sharing, adaptation, distribution and reproduction in any medium or format, as long as you give appropriate credit to the original author(s) and the source, provide a link to the Creative Commons licence, and indicate if changes were made. The images or other third party material in this article are included in the article's Creative Commons licence, unless indicated otherwise in a credit line to the material. If material is not included in the article's Creative Commons licence and your intended use is not permitted by statutory regulation or exceeds the permitted use, you will need to obtain permission directly from the copyright holder. To view a copy of this licence, visit http://creativecommons.org/licenses/by/4.0/.

\section{References}

Alkhalifah T, Tsvankin I (1995) Velocity analysis for transversely isotropic media. Geophysics 60:1550-1566

Berryman JG, Grechka VY, Berge PA (1999) Analysis of Thomsen parameters for finely layered VTI media. Geophys Prospec 47:959-978

Hudson JA (1981) Wave speed and attenuation of elastic waves in material containing cracks. Geophys J Int 22:50
Jakobsen M, Johansen TA (2000) Anisotropic approximations for mudrocks: a Seismic laboratory study. Geophysics 65:1711-1725

Johansen TA, Rudd BO, Jakobsen M (2004) Effect of grain scale alignment on seismic anisotropy and reflectivity of shales. Geophys Prospect 52:133-149

Jones IF, Bridson M, Bernitsas N (2003) Anisotropic ambiguities in TI Media. First Break 21:5

Kaushik B (2009) Seismic anisotropy: geological causes and its implications to reservoir.Geophysics; Ph.D Dissertation, Stanford University

Ogagarue DO, Ebeniro JO, Ehirim CN (2007) Velocity anisotropy in the Niger delta sediments derived from geophysical logs. Niger J Phys 192:237

Reijers TA (2011) Stratigraphy and sedimentology of the Niger Delta. Geologos 17(3):133-162

Reijers TA, Petters SW, Nwajide CS (1997) The Niger delta Basin. In: Selly RC (ed) African Basin-sedimentary Basin of the world 3: Amsterdam. Elservier, Amsterdam

Rudd BO, Jakobsen M, Johansen TA (2003) Seismic properties of shales during compaction. SEG Expand Abstr 22:1294

Sayers CM (1994) The elastic anisotropy of shales. J Geophys Res 99:767-774

Short KC, Stauble AJ (1967) Outline of geology of Niger delta. AAPG Bull 51:761-779

Thomsen L (1986) Weak anisotropy. Geophysics 51:1954-1966

Thomsen L (1988) Reflection seismology over azimuthally anisotropic media. Geophysics 53(3):304-313

Toldi J, Alkhalifah T, Berthet P, Arnaud J, Williamson P, Conche B (1999) Case study of estimation of anisotropy. Lead Edge 18(5):588-593

Tsvankin I (1997) P-wave signatures and notation for transversely isotropic media. Geophysics 53:304-313

Tsvankin I, Thomsen L (1994) Nonhyperbolic reflection moveout in anisotropic media. Geophysics 59:1290-1304

Whiteman AJ (1982) Nigeria; its petroleum geology. Resources and Potential; Trottan, London p, p 394

Publisher's Note Springer Nature remains neutral with regard to jurisdictional claims in published maps and institutional affiliations. 